\title{
Relationships between the regulation of psychological needs satisfaction and symptomatology
}

\author{
António Sol ${ }^{1}$ \& António Branco Vasco ${ }^{1}$ \\ ${ }^{1}$ Faculdade de Psicologia da Universidade de Lisboa, Portugal
}

\begin{abstract}
Framed by the integrative Paradigmatic Complementarity Model, the present study addresses the relationships between regulation and discrepancy in psychological needs satisfaction, and symptomatology. This Model conceptualizes psychological needs as dialectical polarities, suggesting that disorders essentially stem from the inability to regulate their satisfaction. 848 adults participated in this study. The results showed that the regulation of psychological needs satisfaction correlated negatively with symptomatology, whereas discrepancy correlated positively with it. Moreover, the level of that regulation showed predictive value of symptomatology. Non-disordered individuals displayed higher regulation of psychological needs satisfaction and lower discrepancy than disordered ones. In both groups, subjects with a high degree of regulation of both needs of each dialectical polarity generally displayed less symptoms, in comparison with all the others, with a few and non-significant exceptions. These results suggest the importance of regulation and discrepancy in psychological needs satisfaction as related to symptomatology.
\end{abstract}

Keywords: Psychological needs; Discrepancies; Symptomatology; Paradigmatic Complementarity Model.

Relações entre a regulação da satisfação de necessidades psicológicas e a sintomatologia: Enquadrado no Modelo de Complementaridade Paradigmática, de natureza integrativa, o presente estudo versa sobre as relações entre a regulação e a discrepância na satisfação de necessidades psicológicas e a sintomatologia. Este Modelo conceptualiza as necessidades psicológicas como polaridades dialéticas, sugerindo que as perturbações mentais emergem fundamentalmente da incapacidade de regular adequadamente a sua satisfação. 848 adultos participaram neste estudo. Os resultados mostraram que a regulação da satisfação de necessidades psicológicas se correlacionou negativamente com a sintomatologia, enquanto a discrepância naquela regulação se correlacionou positivamente com a mesma variável. Além disso, o nível dessa regulação revelou valor preditivo em relação à sintomatologia. Os indivíduos "não perturbados" apresentaram maior regulação e menor discrepância na satisfação de necessidades psicológicas do que os "perturbados". Em ambos os grupos, regra geral, os indivíduos com elevado grau de regulação da satisfação das necessidades de cada polaridade dialética manifestaram menor sintomatologia, comparativamente a todos os outros, sendo as exceções poucas e não significativas. Estes resultados sugerem a importância da regulação e da discrepância na satisfação das necessidades para o nível de sintomatologia.

Palavras-chave: Necessidades psicológicas; Discrepância; Sintomatologia; Modelo de Complementaridade Paradigmática.

\section{Paradigmatic Complementarity Model (PCM)'s concept of Psychological Needs}

The present study addresses the relationships between regulation and discrepancy in psychological needs satisfaction, and symptomatology, proposing a new theory of psychological needs put forward by PCM (e.g., Vasco, 2012), an integrative model that stresses the importance of psychological needs for adaptation and disorder.

More specifically, the present study aims to: a) analyze how the regulation and discrepancy in psychological needs satisfaction may be related to symptomatology, and b) how different degrees of that regulation may be associated with the symptomatology. Based on the literature review that follows and considering the aforesaid objectives, we expect as hypotheses that:

1. Both regulation and discrepancy in psychological needs satisfaction correlate significantly with symptomatology, with higher values of regulation and lower values of discrepancy corresponding to lower values of symptomatology;

2. The regulation of psychological needs satisfaction predicts the level of symptomatology;

${ }^{1}$ Address for correspondence: António Sol, Serviço à Comunidade da Faculdade de Psicologia da Universidade de Lisboa, Alameda da Universidade, Cidade Universitária, 1649-013 Lisboa, Portugal. E-mail: antonioluzsol@hotmail.com. 
3. Individuals with a high degree of regulation of both needs of each dialectical polarity display lower levels of symptomatology than individuals with a low degree of regulation of both poles or a high degree of regulation of just one of them, both within non-disordered and disordered subjects.

PCM defines psychological needs as "a state of organismic imbalance due to the lack or excess of certain psychological nutrients, emotionally signaled, and aiming to promote internal and/or external actions tending to restore the balance" (Vasco, 2012).

Grounded on the former theories of psychological needs, such as Maslow's pyramid of needs (1954), Deci and Ryan's self-determination theory (2000), Epstein's cognitive-experiential self-theory $(1990,1991,1993,2003)$, and Grawe (2004), and on the construct of polarity of experience of Blatt's personality theory $(2006,2008)$, the PCM suggests an integrative theory of psychological needs, with contributions from different theoretical orientations, putting forward the following dialectical polarities of psychological needs (e.g., Faria \& Vasco, 2011; Vasco \& Velho, 2010): pleasure (ability to experience and enjoy both psychological and physical pleasures) / pain (ability to endure inevitable pain, ability to give meaning to pain); proximity (ability to establish and maintain intimate relationships) / differentiation (ability to differentiate and to be self-determined); productivity (ability to accomplish worth feeling deeds) / leisure (ability to relax and feel comfortable with it); control (ability to influence environments) / cede/cooperation (ability to delegate, to let go); actualization/exploration (ability to explore, exposure to newness) / tranquility (ability to appreciate what one has); coherence of self (congruence between experienced and ideal self, congruence between what one thinks, feels and does) / incoherence of self (ability to tolerate conflict and occasional incongruences); and self-esteem (ability to feel satisfied with oneself) / self-criticism (ability to identify, tolerate and learn from personal dissatisfactions).

Contrary to Maslow (1954) and similar to Deci and Ryan (2000), Epstein (2003), and Grawe (2004), there is not any hierarchy among the several polarities (even though some of them may better explain the variability of well-being and symptomatology). However, contrary to the referred theories, the PCM suggests that needs are not one-dimensional, being conceptualized as dialectical polarities, that is, pairs of needs that mutually interact, influencing each other in a reciprocal and synergistic way, similar to the fundamental polarity of experience of Blatt's self-definition - relatedness $(2006,2008)$. In other words, within each dialectical polarity, the level of regulation of one of the needs facilitates and promotes the level of regulation of the other, and vice versa. For instance, regarding the polarity self-esteem/selfcriticism, the acknowledgment, acceptance, and learning from personal defaults (healthy self-criticism) will certainly contribute to a qualitatively better and more realistic self-esteem, allowing the individual to appreciate the own's self, with qualities and defaults, notwithstanding the fact of wanting to change some personal aspects.

Psychological needs are never fully satisfied: their degree of satisfaction result from a never ending ongoing process of negotiating and balancing dialectical polarities (Faria \& Vasco, 2011; Vasco, 2012). Psychological well-being depends on the personal ability to regulate properly the satisfaction of the various needs. This regulation process is dialectical on two levels, horizontal (within each polarity) and vertical (among the polarities). In other words, regulating properly psychological needs satisfaction is knowing how to move with flexibility within each polarity and among all the polarities, which complement and do not contradict each other (Faria \& Vasco, 2011). Therefore, like the personality theory of Blatt $(2006,2008)$, the PCM also suggests that adaptation demands a dialectical and dynamic balance between complementary opposites.

According to the PCM, psychological needs are important for the understanding not only of adaptation but also of disorder. It is likely that mental disorders stem from unbalances on the regulation of psychological needs satisfaction (Faria \& Vasco, 2011). Therefore, the inability to regulate properly needs satisfaction seems to contribute to disorder. Dysregulation can be horizontal (within a polarity - for instance, regarding the polarity self-esteem-self-criticism, not being able to like oneself, accepting one's defaults and vulnerabilities), or vertical (among polarities - for instance, between control and proximity).

For the PCM, mental disorders may result from rigidity around any pole, as none of both sides is "pathological" per se. For instance, regarding once again the polarity self-esteem-self-criticism, it is not only the rigidity of self-criticism that can be pathological, leading to mental disorders such as depression or dystimia. Also, the fixation on self-esteem, without space for self-criticism, will certainly be pathological (as seen on narcissistic personality disorder).

The PCM denies any idea of a priori good and bad needs, regardless of the circumstances of the internal and/or external environment, suggesting the construct of "needs without valence", meaning that all needs can be adaptive or pathological (Conceição \& Vasco, 2005). These authors prefer to use the construct of "pathology of needs" instead of "pathological needs". So, the pathology of needs does not refer to the needs themselves, but to dysfunctional processes under their regulation or inadequate ways of regulating them. Conceição and Vasco (2005) suggest five dimensions underlying the pathology of needs: 
“(a) Not acknowledging and/or not validating one's needs; (b) Not differentiating and/or not relating to one's needs; (c) Not choosing and/or not compromising with one's needs; (d) Not allowing satisfaction and/or frustration of one's needs; (e) Not actualizing and/or not transcending one's needs" (pp. 70-71).

Apart from their importance for adaptation and disorder, psychological needs are also relevant for intervention. Vasco (2012) considers that, possibly for a significant number of patients, the goals of therapy should be not only to alleviate symptoms, but also to help them to acknowledge, accept, experience, and act upon the regulation of the satisfaction of vital psychological needs. In their turn, Faria and Vasco (2011) stress the importance of psychological needs for case conceptualization, facilitating the process of clinical decision-making. As far as intervention is concerned, Vasco (2009) suggests some ways to work with dysregulations of proximity-autonomy (namely, through empathy, warmth, and positive regard; collaborative communication in terms of responsiveness, syntony, regulating distance, and level of intervention; emotional communication; and reflexive dialogue; see also Vasco, 2007) and coherenceincoherence of Self (for instance, through emotional validation of conflict and inconsistencies; coherent narratives; and two-chair work to deal with self-critical and interruptive splits).

\section{Relationships among regulation and balance versus discrepancy in psychological needs satisfaction, and psychological distress and symptomatology}

As aforesaid, several theories argue that needs satisfaction is crucial for mental health. In case needs satisfaction is not properly regulated, there are detrimental consequences in terms of symptomatology and distress (Deci \& Ryan, 2000; Faria \& Vasco, 2011; Grawe, 2004; Vasco \& Velho, 2010).

Faria and Vasco (2011) studied the relationships between the regulation of psychological needs satisfaction and mental disorders, having found that patients with higher symptomatology seemed to be less able to regulate their needs satisfaction, with the exception of the polarity productivity/leisure. The polarities that seemed to contribute the most to disorder were self-esteem-self-criticism and coherenceincoherence of self. On an analysis of variance, in proximity-differentiation, pleasure-pain, control-cede and self-esteem-self-criticism, patients who were higher on the ability to regulate both poles of the referred polarities were less disturbed than those who were less able to regulate them.

In another study, Vasco, Faria, Vaz, and Conceição (2010) investigated the relationship among psychological needs dissatisfaction, emotional dysregulation and mental disorders, having found significant negative correlations between needs satisfaction and disorders. Moreover, needs displayed much more predictive value of disorders than emotional dysregulation, which only predicted impulse control difficulties and even though in a very low way.

In their turn, Bernardo (2011), Calinas (2011), Fonseca (2011), Guerreiro (2011), Rodrigues (2010), and Rucha (2011), in studies on proximity/differentiation, actualization-exploration/tranquility, control/cede-cooperation, self-esteem/self-criticism, coherence/incoherence and productivity/leisure, performed multivariate analysis of variance in non-clinical convenience samples composed by adults, comparing groups based on the degree of regulation of the aforesaid dialectical polarities, on psychological well-being and distress. In all groups, the one with a high degree of regulation of both needs of each polarity displayed higher values of well-being and lower values of distress than all the others. As far as the polarity pleasure/pain is concerned, although the group with the lowest value of distress was also the one with a high degree of regulation of both pleasure and pain, the group with the highest wellbeing was the one with high regulation of pleasure and low regulation of pain, even though it was immediately followed by the one with high regulation of both needs, without significant differences between them (Cadilha, 2010).

Regarding the balance and discrepancy in psychological needs satisfaction, Sheldon and Niemiec (2006) performed four studies to investigate the relationship between the amount and balance in needs satisfaction (autonomy, competence, and relatedness), the three needs of self-determination theory (Deci \& Ryan, 2000), on one hand, and well-being and adjustment, on the other. Although the effect sizes of the positive impact of balance on well-being were modest, having the amount of needs satisfaction displayed higher effects, the balance effect turned up consistently in all studies, with different designs (crosssectional and longitudinal) and methodologies (daily diary and multiple reporter). Moreover, the balance effect remained, even when neuroticism, the total amount of need satisfaction and the curvilinear effects of satisfaction were controlled.

Sirgy and $\mathrm{Wu}$ (2009) also suggested that balance in the satisfaction of several human needs performs an important role on the level of subjective well-being. According to them, people should be involved in multiple domains (e.g., education, family, health, work, friendships, romantic relationships, among others) to satisfy their needs, because there is a satisfaction limit that people can derive from a single life domain and the different life domains tend to refer to different human needs. Apart from this, subjective well-being depends on the satisfaction of both survival and growth needs. They are all 
necessary and none of them is per se enough.

As previously mentioned, Grawe (2004) considers consistency as the basic principle of mental functioning, defining it as "the agreement or compatibility of simultaneously transpiring neural/mental processes" (p. 168). There is evidence from several experimental and correlational studies that inconsistency is detrimental to mental health, being related to mental disorder and symptomatology.

Grawe (2004) identified several kinds of inconsistency, such as interference of two or more processes (e.g., the Stroop color test), cognitive dissonance (two cognitions mutually relevant and incompatible, which lead to an unpleasant psychological state), dissociation (present in several mental disorders, such as in dissociative personality disorder or in posttraumatic stress disorder), motivational conflicts (approach-approach conflicts; approach-avoidance conflicts; avoidance-avoidance conflicts; double approach-avoidance conflicts; avoidance-approach conflicts), discrepancies between various types of self-representation, such as the actual-self, ideal-self and ought-self (Higgins, as cited in Grawe, 2004), and incongruence, which is the inconsistency between motivational goals and the extent to which the goals have been attained. Grawe considers this last one as perhaps the most important form of inconsistency.

From our point of view, discrepancies in psychological needs satisfaction can be considered as a kind of inconsistency, with detrimental consequences for mental health, like the incongruence studied by Grawe (2004).

\section{METHOD}

\section{Participants and procedures}

Data were collected from March to May 2012 by means of a platform containing the measures participants completed online. As can be seen on Table 1, it was a convenience sample with the following criteria: to be more than 18 years old; to have at least the $9^{\text {th }}$ school degree or equivalent (to ensure that the participants had a level of literacy that allowed them to understand what they were asked to fill in); to have Portuguese as mother tongue. Some data were also collected to characterize the sample: sex, age, academic qualifications ( $9^{\text {th }}$ grade or equivalent; $12^{\text {th }}$ grade or equivalent; Bachelorship; Licentiateship; Master; $\mathrm{PhD}$ ), and if they were at that moment having psychological, psychotherapeutic or psychiatric support. Participation was anonymous. All participants gave their informed consent to participate in the study. Table 1 presents the characteristics of the global sample and the subsamples.

Table 1. Characteristics of the global sample and the subsamples.

\begin{tabular}{|c|c|c|c|}
\hline Characteristics & $\mathrm{ERSN}^{2}(\% ; N=848)$ & $\operatorname{CORE}-\mathrm{OM}^{3}(\% ; N=501)$ & $\mathrm{BSI}^{4}(\% ; N=436)$ \\
\hline \multicolumn{4}{|l|}{ Age (years) } \\
\hline$M$ & 28.41 & 28.09 & 28.28 \\
\hline$S D$ & 11.075 & 10.815 & 11.075 \\
\hline Minimum & 18 & 18 & 18 \\
\hline Maximum & 77 & 77 & 77 \\
\hline \multicolumn{4}{|l|}{ Sex } \\
\hline Male & $170(20 \%)$ & $95(19 \%)$ & $87(20 \%)$ \\
\hline Female & $678(80 \%)$ & $406(81 \%)$ & $349(80 \%)$ \\
\hline \multicolumn{4}{|l|}{ Therapeutic support } \\
\hline Yes & $114(13.4 \%)$ & $74(14.8 \%)$ & $68(15.6 \%)$ \\
\hline No & $734(86.6 \%)$ & $427(85.2 \%)$ & $368(84.4 \%)$ \\
\hline \multicolumn{4}{|l|}{ Marital status } \\
\hline Without stable romantic relationship & $402(47.4 \%)$ & $253(50.5 \%)$ & $220(50.5 \%)$ \\
\hline With stable romantic relationship & $446(52.6 \%)$ & $248(49.5 \%)$ & $216(49.5 \%)$ \\
\hline \multicolumn{4}{|l|}{ Educational Qualifications } \\
\hline 9th grade or equivalent & $10(1.2 \%)$ & $5(1 \%)$ & $4(0.9 \%)$ \\
\hline 12 th grade or equivalent & $319(37.6 \%)$ & $188(37.5 \%)$ & $167(38.3 \%)$ \\
\hline Bachelorship & $22(2.6 \%)$ & $11(2.2 \%)$ & $10(2.3 \%)$ \\
\hline Licentiateship & $358(42.2 \%)$ & 227 (45.3\%) & $195(44.7 \%)$ \\
\hline Masters & $133(15.7 \%)$ & 67 (13.4\%) & $58(13.3 \%)$ \\
\hline Ph.D. & $6(0.7 \%)$ & $3(0.6 \%)$ & $2(0.5 \%)$ \\
\hline
\end{tabular}

${ }^{2}$ Psychological Needs Satisfaction Regulation Scale ("Escala de Regulação da Satisfação de Necessidades Psicológicas”) (Vasco et al., 2012).

${ }^{3}$ Clinical Outcome Routine Evaluation - Outcome Measure (Evans et al., 2000; Portuguese version by Sales, Moleiro, Evans, \& Alves, 2012).

${ }^{4}$ Brief Symptom Inventory (Derogatis, 1993; portuguese version by Canavarro, 2007). 


\section{Measures}

Psychological Needs Satisfaction Regulation Scale (ERSN)

Regulation and discrepancy in psychological needs satisfaction were measured with the ERSN (Vasco et al., 2012). It is a self-report instrument based on the literature on psychological needs, with 14 subscales related to each need proposed by the PCM: pleasure (8 items; e.g., "I feel I can get pleasure from life"); pain (3 items; e.g., "I understand that pain is productive sometimes"); proximity (6 items; e.g., "I enjoy being with other people"); differentiation (5 items; e.g., "It's comfortable to be with myself"); productivity (15 items; e.g., "I'm satisfied with the quality of what I produce"); leisure (13 items; e.g., "Leisure is so important as any other area of my life"); control (14 items; e.g., "I feel I'm in control of my inner reality"); cede/cooperation (13 items; e.g., "I believe I must act in a cooperative way with society"); actualization/exploration (12 items; e.g., "In a general way, I like to experience new things"); tranquility (11 items; e.g., "I experience an inner serenity that doesn't depend on external events"); coherence of self (6 items; e.g., "I feel myself close to the person I wish to be"); incoherence of self (7 items; e.g., "When I feel incoherencies or conflicts between opposite emotions, I accept their existence and try to solve them"); self-esteem (12 items; e.g., "In a general way, I'm satisfied with myself"); and self-criticism (10 items; e.g., "I'm able to differentiate between constructive and destructive criticisms"). In turn, these 14 subscales can be aggregated into seven subscales corresponding to the dialectical polarities suggested by the Model (Vasco, 2012). These seven subscales result from the mean of both poles of each dialectical polarity. Initially composed of 160 items, this scale was reformulated following a study on its psychometric characteristics (Conde, 2012), having been reduced to 135 items. The answer to each item is expressed in a Likert-type scale, ranging from 1 (I completely disagree) to 8 (I completely agree). Points 4 and 5 divide, respectively, disagreement and agreement. Table 2 presents the ERSN's internal consistency in the original studies of each polarity (Cadilha, 2010; Bernardo, 2011; Rucha, 2011; Fonseca, 2011; Calinas, 2011; Rodrigues, 2010; Guerreiro, 2011) and in the present study.

Table 2. ERSN's internal consistency (Cronbach's alpha).

\begin{tabular}{|c|c|c|}
\hline & Original studies & Present study \\
\hline Global ERSN & & .98 \\
\hline Pleasure & .73 & .83 \\
\hline Pain & .75 & .48 \\
\hline Pleasure-Pain & .77 & .78 \\
\hline Proximity & .83 & .84 \\
\hline Differentiation & .64 & .73 \\
\hline Proximity-Differentiation & .84 & .84 \\
\hline Productivity & .92 & .94 \\
\hline Leisure & .89 & .90 \\
\hline Productivity-Leisure & .93 & .94 \\
\hline Control & .86 & .87 \\
\hline Cede/cooperation & .85 & .87 \\
\hline Control-Cede/cooperation & .90 & .91 \\
\hline Actualization/exploration & .82 & .84 \\
\hline Tranquility & .85 & .86 \\
\hline Actualization/exploration-Tranquility & .88 & .89 \\
\hline Coherence of self & .81 & .85 \\
\hline Incoherence of self & .72 & .82 \\
\hline Coherence-Incoherence & .85 & .89 \\
\hline Self-esteem & .92 & .92 \\
\hline Self-criticism & .81 & .84 \\
\hline Self-esteem-Self-criticism & .91 & .91 \\
\hline
\end{tabular}

Brief Symptom Inventory (BSI)

Symptomatology was measured with the BSI (Derogatis, 1993; Portuguese version by Canavarro, 2007). BSI is a very well-known self-report composed of 53 itens, using a Likert-type scale, ranging from 0 (not at all) to 4 (extremely). The reliability for this measure in this study was very high, $\alpha=.97$.

Clinical Outcome Routine Evaluation - Outcome Measure (CORE-OM)

We used another measure for symptomatology, CORE-OM (Evans et al., 2000; Portuguese version by Sales, Moleiro, Evans, \& Alves, 2012), a European self-report for adults, to ensure convergent validity. It is composed of 34 items, using a Likert-type scale, ranging from 0 (not at all) to 4 (most or all the time). In 
this study, the reliability for this measure was also very high, $\alpha=.96$.

\section{RESULTS}

\section{Correlations}

Tables 3 and 4 presents the correlations between psychological needs and dialectical polarities, on one hand, and BSI and CORE-OM, on the other hand.

Table 3. Correlations between psychological needs and BSI $(n=436)$ and CORE-OM $(n=501)$.

\begin{tabular}{llc}
\hline Symptomatology Needs & BSI & CORE-OM \\
\hline Pleasure & $-.70^{*}$ & $-.61^{*}$ \\
Pain & $-.15^{*}$ & $-.16^{*}$ \\
Proximity & $-.69^{*}$ & $-.63^{*}$ \\
Differentiation & $-.56^{*}$ & $-.49^{*}$ \\
Productivity & $-.69^{*}$ & $-.59^{*}$ \\
Leisure & $-.61^{*}$ & $-.52^{*}$ \\
Control & $-.64^{*}$ & $-.57^{*}$ \\
Cede/Cooperation & $-.51^{*}$ & $-.50^{*}$ \\
Actualization/Exploration & $-.43^{*}$ & $-.38^{*}$ \\
Tranquility & $-.76^{*}$ & $-.65^{*}$ \\
Coherence & $-.64^{*}$ & $-.55^{*}$ \\
Incoherence & $-.61^{*}$ & $-.57^{*}$ \\
Self-esteem & $-.77^{*}$ & $-.66^{*}$ \\
Self-criticism & $-.39^{*}$ & $-.40^{*}$ \\
\hline
\end{tabular}

Note. ${ }^{*} p<.01$

Table 4. Correlations between dialectical polarities and BSI $(n=436)$ and CORE-OM $(n=501)$.

\begin{tabular}{lcc}
\hline Polarities Symptomatology & BSI & CORE-OM \\
\hline Pleasure-Pain & $-.58^{*}$ & $-.66^{*}$ \\
Proximity-Differentiation & $-.65^{*}$ & $-.72^{*}$ \\
Productivity-Leisure & $-.62^{*}$ & $-.73^{*}$ \\
Control-Cede/Cooperation & $-.59^{*}$ & $-.63^{*}$ \\
Actualization/Exploration-Tranquility & $-.60^{*}$ & $-.68^{*}$ \\
Coherence-Incoherence & $-.61^{*}$ & $-.68^{*}$ \\
Self-esteem-Self-criticism & $-.64^{*}$ & $-.72^{*}$ \\
\hline
\end{tabular}

Note. ${ }^{*} p<.01$.

As far as the psychological needs are concerned, all of them presented negative correlations with both BSI and CORE-OM, as supposed to. The strength of those correlations was large, with the exception of actualization/exploration and self-criticism, which were correlated with those measures to a medium extent, and of pain, with just small correlations with symptomatology.

As expected, the correlations between all polarities and both BSI and CORE-OM were negative and strong. The strength of the correlations was slightly larger with CORE-OM than with BSI.

Table 5 presents the correlations between discrepancies on the seven dialectical polarities (computed by way of the difference in modulus between both poles of each dialectical polarity) and the global discrepancy (the sum of the polarities' discrepancies), on one hand, and BSI and CORE-OM, on the other.

Table 5. Correlations between discrepancies in dialectical polarities and BSI $(n=436)$ and CORE-OM $(n=$ 501).

\begin{tabular}{llc}
\hline Discrepancies Symptomatology & BSI & CORE-OM \\
\hline Pleasure-Pain & $.14^{*}$ & $.12^{*}$ \\
Proximity-Differentiation & .00 & .01 \\
Productivity-Leisure & $.23^{*}$ & $.25^{*}$ \\
Control-Cede/Cooperation & $.26^{*}$ & $.32^{*}$ \\
Actualization/Exploration-Tranquility & $.39^{*}$ & $.47^{*}$ \\
Coherence-Incoherence & .08 & .05 \\
Self-esteem-Self-criticism & $.46^{*}$ & $.56^{*}$ \\
Global Discrepancy & $.43^{*}$ & $.49^{*}$ \\
\hline
\end{tabular}

Note. ${ }^{*} p<.01$ 
There was no relationship between discrepancies in proximity-differentiation and coherenceincoherence and BSI and CORE-OM. Regarding the other polarities, there was a positive correlation between the respective discrepancies and BSI and CORE-OM, as expected. The strength of those correlations ranged from small to large. The global discrepancy and the discrepancy in self-esteem-selfcriticism were the most related to symptomatology.

\section{Predictive value of psychological needs in relation to symptomatology}

The predictive value of the 14 psychological needs and the seven dialectical polarities suggested by the PCM (e.g., Vasco, 2012), in relation to symptomatology, measured with the BSI and CORE-OM, was analyzed using first standard multiple regressions and then, as supplementary analyses, stepwise multiple regressions.

Tables 6 and 7 present the results of standard multiple regressions of psychological needs and dialectical polarities, respectively, in relation to both BSI and CORE-OM.

Table 6. Summary of standard multiple regression analyses for psychological needs predicting BSI ( $\mathrm{n}=$ 436) and CORE-OM ( $n=501)$

\begin{tabular}{|c|c|c|c|c|c|c|}
\hline & \multicolumn{3}{|c|}{ BSI } & \multicolumn{3}{|c|}{ CORE-OM } \\
\hline & $B$ & $S E B$ & $\beta$ & $B$ & $S E B$ & $\boldsymbol{\beta}$ \\
\hline Pleasure & -.008 & .004 & -.123 & -.010 & .003 & -.149 \\
\hline Pain & .007 & .006 & .046 & .006 & .005 & .034 \\
\hline Proximity & -.021 & .004 & -.254 & -.021 & .003 & -.251 \\
\hline Differentiation & -.004 & .004 & -.044 & -.003 & .003 & -.032 \\
\hline Productivity & -.003 & .002 & -.113 & -.004 & .002 & -.132 \\
\hline Leisure & .001 & .002 & .030 & .000 & .002 & .006 \\
\hline Control & -.001 & .003 & -.023 & .000 & .002 & -.005 \\
\hline Cede/Cooperation & -.003 & .003 & -.069 & -.001 & .002 & -.014 \\
\hline Actualization/Exploration & .005 & .002 & .101 & .007 & .002 & .122 \\
\hline Tranquility & -.012 & .003 & -.269 & -.019 & .002 & -.389 \\
\hline Coherence & .010 & .005 & .132 & .006 & .004 & .083 \\
\hline Incoherence & -.014 & .004 & -.205 & -.007 & .003 & -.103 \\
\hline Self-esteem & -.002 & .004 & -.042 & -.005 & .003 & -.121 \\
\hline Self-criticism & .001 & .003 & .023 & .005 & .002 & .072 \\
\hline$R^{2}$ & \multicolumn{3}{|c|}{.551} & \multicolumn{3}{|c|}{.707} \\
\hline$F$ & \multicolumn{3}{|c|}{$36.873^{*}$} & \multicolumn{3}{|c|}{$83.634^{*}$} \\
\hline
\end{tabular}

As we can see, the 14 psychological needs explained more of the variance in CORE-OM (70.7\%) than in BSI (55.1\%). Apart from this, the psychological needs which explained more unique variance in both BSI and CORE-OM were tranquility and proximity. On the contrary, the ones which explained less unique variance were control and leisure, in both BSI and CORE-OM, as well as self-criticism, in BSI, and cede/cooperation, in CORE-OM.

Table 7. Summary of standard multiple regression analyses for dialectical polarities predicting BSI $(n=$ 436) and CORE-OM ( $\mathrm{n}=501)$

\begin{tabular}{|c|c|c|c|c|c|c|}
\hline & \multicolumn{3}{|c|}{ BSI } & \multicolumn{3}{|c|}{ CORE-OM } \\
\hline & $\boldsymbol{B}$ & $S E B$ & $\beta$ & $\boldsymbol{B}$ & $S E B$ & $\boldsymbol{\beta}$ \\
\hline Pleasure-Pain & -.002 & .003 & -.043 & -.003 & .003 & -.047 \\
\hline Proximity- Differentiation & -.015 & .003 & -.300 & -.016 & .002 & -.307 \\
\hline Productivity-Leisure & -.001 & .001 & -.076 & -.004 & .001 & -.203 \\
\hline Control- Cede/Cooperation & -.001 & .002 & -.059 & .001 & .001 & .047 \\
\hline Actualization/Exploration- Tranquility & -.002 & .002 & -.083 & -.004 & .002 & -.146 \\
\hline Coherence-Incoherence & -.006 & .003 & -.151 & -.006 & .002 & -.139 \\
\hline Self-esteem-Self-criticism & -.002 & .002 & -.074 & -.002 & .002 & -.080 \\
\hline$R^{2}$ & \multicolumn{3}{|c|}{.489} & \multicolumn{3}{|c|}{.621} \\
\hline$F$ & \multicolumn{3}{|c|}{$58.453^{*}$} & \multicolumn{3}{|c|}{$115.244^{*}$} \\
\hline
\end{tabular}

Note. ${ }^{*} p<.001$.

As far as the dialectical polarities are concerned and like the psychological needs, they explained more of the variance in CORE-OM (62.1\%) than in BSI (48.9\%). Looking further, the ones which explained more unique variance in both BSI and CORE-OM were proximity-differentiation, productivity-leisure and 
coherence-incoherence, although these last two were displayed in a different order in the two dependent variables. On the contrary, the dialectical polarities that explained less unique variance both in BSI and CORE-OM were pleasure-pain and control-cede/cooperation.

Regarding the stepwise multiple regression, as a supplementary analysis, of the 14 needs suggested by the PCM in relation to symptomatology (measured with BSI), the best model indicated that 54.6\% of the global variance in symptomatology was explained by four needs, proximity, $\beta=-.332, t(435)=-$ 7.773, $p<.001$, tranquility, $\beta=-.252, t(435)=-4.382, p<.001$, incoherence, $\beta=-.156, t(435)=-3.274, p$ $=.001$, and self-esteem, $\beta=-.131, t(435)=-2.108, p=.036$, being the result statistically significant, $R a^{2}$ $=.546, F(4,431)=131.764, p<.001$.

Concerning the predictive power of dialectical polarities in relation to symptomatology (measured with BSI), the best model explained $48.3 \%$ of the global variance in BSI, $R a^{2}=.483, F(3,432)=136.333, p$ $<.001$, being composed of the polarities proximity-differentiation, $\beta=-.364, t(435)=-7.085, p<.001$, self-esteem-self-criticism, $\beta=-.202, t(435)=-2.859, p=.004$, and coherence-incoherence, $\beta=-.201$, $t(435)=-3.161, p=.002$.

We performed another stepwise multiple regression analyses for symptomatology measured with CORE-OM. Using the 14 psychological needs as predictors, the best model explained $71.1 \%$ of the global variance in CORE-OM, $R_{a}^{2}=.711, F(5,495)=246.520, p<.001$, being composed of tranquility, $\beta=-.362$, $t(500)=-8.370, p<.001$, proximity, $\beta=-.296, t(500)=-9.080, p<.001$, self-esteem, $\beta=-.218, t(500)=-$ 4.684, $p<.001$, pleasure, $\beta=-.157, t(500)=-3.787, p<.001$, and actualization/exploration, $\beta=-.105$, $t(500)=-3.363, p=.001$.

Regarding the predictive power of dialectical polarities in relation to CORE-OM, the best model explained $62.2 \%$ of the global variance in CORE-OM, $R_{a}^{2}=.622, F(4,496)=206.665, p<.001$, having been selected the polarities proximity-differentiation, $\beta=-.326, t(500)=-7.493, p<.001$, productivity-leisure, $\beta=-.240, t(500)=-4.625, p<.001$, coherence-incoherence, $\beta=-.175, t(500)=-3.776, p<.001$, and actualization/exploration-tranquility, $\beta=-.142, t(500)=-2.906, p=.004$.

Comparing both models for BSI and CORE-OM, tranquility, proximity, and self-esteem were common predictors, as well as the polarities proximity-differentiation and coherence-incoherence. Apart from this, both the 14 needs and the seven dialectical polarities explained more variance in CORE-OM than in BSI. Finally, both in BSI and CORE-OM, the 14 needs explained more variance than the seven polarities (in BSI, $R a^{2}=54.6 \%>R a^{2}=48.3 \%$, and in CORE-OM, $R a^{2}=71.1 \%>R a^{2}=62.2 \%$ ).

\section{Analysis of variance}

The effect of the degree of regulation of psychological needs satisfaction on symptomatology (measured with BSI and CORE-OM), both within non-disordered and disordered individuals, was investigated with a MANOVA. The normality of the dependent variables was assessed with the Kolmogorov-Smirnov's test. Both variables had normal distribution in the disordered group $(p=.200>\alpha=.05)$, but not in the nondisordered one $(p<.05)$. However, once there was the assumption of homogeneity of variance-covariance, assessed with the Box's M test, in all groups, with the exception of the non-disordered group for the dialectical polarity actualization/exploration-tranquility, and given that MANOVA is more robust than the non-parametric alternatives, in case of violation of normality, especially in larger samples (Maroco, 2007), we decided to use the aforesaid parametric test.

The sample was divided into two groups, without and with disorder, based on the BSI's PSDI cut point of 1.70 (Canavarro, 2007). Within each of the aforesaid subsamples, four groups were created regarding the results obtained in the several dialectical polarities. To generate these groups, we divided the results of both poles of each dialectical polarity by the respective medians, considering high the level equal or above that value and low the level under it. Then we created for each dialectical polarity the four possible combinations corresponding to four groups: group $1(--)$; group $2(-+)$; group $3(+-)$; and group $4(++)$. Table 8 presents the medians of both poles of each dialectical polarity.

Table 8. Medians of both poles of each dialectical polarity

\begin{tabular}{lc}
\hline Needs & Median \\
\hline Pleasure & 5.88 \\
Pain & 5.67 \\
Proximity & 7.08 \\
Differentiation & 5.60 \\
Productivity & 6.07 \\
Leisure & 6.15 \\
Control & 5.79 \\
Cede/Cooperation & 6.38
\end{tabular}


Table 9 presents the results of MANOVA in the two subsamples, non-disordered and disordered individuals.

Table 9. MANOVA' s results

\begin{tabular}{|c|c|c|c|c|c|c|c|}
\hline Polarities & Groups & $\begin{array}{c}\text { Pillai's } \\
\text { Trace }\end{array}$ & $F$ & $\begin{array}{c}\text { Hypothesis } \\
\text { df }\end{array}$ & $\begin{array}{c}\text { Error } \\
d f\end{array}$ & Sig. & $\begin{array}{l}\text { Partial Eta } \\
\text { Squared }\end{array}$ \\
\hline \multirow[t]{2}{*}{ Regulation of Pleasure-Pain } & 1 & .268 & 13.406 & 6 & 520 & .000 & .134 \\
\hline & 2 & .227 & 6.864 & 6 & 322 & .000 & .113 \\
\hline \multirow[t]{2}{*}{ Regulation of Proximity-Differentiation } & 1 & .295 & 14.980 & 6 & 520 & .000 & .147 \\
\hline & 2 & .345 & 11.171 & 6 & 322 & .000 & .172 \\
\hline \multirow[t]{2}{*}{ Regulation of Productivity-Leisure } & 1 & .371 & 19.759 & 6 & 520 & .000 & .186 \\
\hline & 2 & .237 & 7.232 & 6 & 322 & .000 & .119 \\
\hline \multirow[t]{2}{*}{ Regulation of Control-Cede/Cooperation } & 1 & .273 & 13.702 & 6 & 520 & .000 & .137 \\
\hline & 2 & .207 & 6.212 & 6 & 322 & .000 & .104 \\
\hline \multirow[t]{2}{*}{ Regulation of Actualization/Exploration-Tranquility } & 1 & .357 & 18.808 & 6 & 520 & .000 & .178 \\
\hline & 2 & .333 & 10.733 & 6 & 322 & .000 & .167 \\
\hline \multirow[t]{2}{*}{ Regulation of Coherence-Incoherence } & 1 & .300 & 15.280 & 6 & 520 & .000 & .150 \\
\hline & 2 & .285 & 8.913 & 6 & 322 & .000 & .142 \\
\hline \multirow[t]{2}{*}{ Regulation of Self-esteem-Self-criticism } & 1 & .373 & 19.892 & 6 & 520 & .000 & .187 \\
\hline & 2 & .354 & 11.555 & 6 & 322 & .000 & .177 \\
\hline
\end{tabular}

Note. Group 1 = Non-disordered individuals; Group 2 = Disordered individuals.

According to the MANOVA's results, the degree of regulation of all dialectical polarities satisfaction had a significant effect on the multivariate composite of symptomatology (measured with BSI and CORE$\mathrm{OM}$ ), both within non-disordered and disordered individuals (for all polarities and groups, $p<.001$ ).

Table 10 presents the results of the univariate ANOVA for each dependent variable, for both nondisordered and disordered groups.

Table 10. Univariate ANOVA for BSI and CORE-OM, within non-disordered and disordered individuals

\begin{tabular}{|c|c|c|c|c|c|c|c|}
\hline Polarities & Groups & $\begin{array}{c}\text { Dependent } \\
\text { variables }\end{array}$ & $\boldsymbol{F}$ & $d f$ & Error & Sig. & $\begin{array}{c}\text { Partial } \\
\text { Eta } \\
\text { Squared }\end{array}$ \\
\hline \multirow[t]{4}{*}{ Regulation of Pleasure-Pain } & \multirow[t]{2}{*}{1} & CORE-OM & 29.679 & 3 & 260 & .000 & .255 \\
\hline & & BSI & 14.774 & 3 & 260 & .000 & .146 \\
\hline & \multirow[t]{2}{*}{2} & CORE-OM & 14.835 & 3 & 161 & .000 & .217 \\
\hline & & BSI & 4.989 & 3 & 161 & .002 & .085 \\
\hline \multirow[t]{4}{*}{ Regulation of Proximity-Differentiation } & \multirow[t]{2}{*}{1} & CORE-OM & 27.866 & 3 & 260 & .000 & .243 \\
\hline & & BSI & 26.546 & 3 & 260 & .000 & .234 \\
\hline & \multirow[t]{2}{*}{2} & CORE-OM & 27.214 & 3 & 161 & .000 & .336 \\
\hline & & BSI & 16.101 & 3 & 161 & .000 & .231 \\
\hline \multirow[t]{4}{*}{ Regulation of Productivity-Leisure } & \multirow[t]{2}{*}{1} & CORE-OM & 49.427 & 3 & 260 & .000 & .363 \\
\hline & & BSI & 20.914 & 3 & 260 & .000 & .194 \\
\hline & \multirow[t]{2}{*}{2} & CORE-OM & 16.128 & 3 & 161 & .000 & .231 \\
\hline & & BSI & 8.358 & 3 & 161 & .000 & .135 \\
\hline \multirow[t]{4}{*}{ Regulation of Control-Cede/Cooperation } & \multirow[t]{2}{*}{1} & CORE-OM & 25.380 & 3 & 260 & .000 & .227 \\
\hline & & BSI & 14.360 & 3 & 260 & .000 & .142 \\
\hline & \multirow[t]{2}{*}{2} & CORE-OM & 8.518 & 3 & 161 & .000 & .137 \\
\hline & & BSI & 13.339 & 3 & 161 & .000 & .199 \\
\hline \multirow[t]{4}{*}{ Regulation of Actualization/Exploration-Tranquility } & \multirow[t]{2}{*}{1} & CORE-OM & 43.599 & 3 & 260 & .000 & .335 \\
\hline & & BSI & 22.541 & 3 & 260 & .000 & .206 \\
\hline & \multirow[t]{2}{*}{2} & CORE-OM & 25.416 & 3 & 161 & .000 & .321 \\
\hline & & BSI & 10.879 & 3 & 161 & .000 & .169 \\
\hline
\end{tabular}




\begin{tabular}{llllllll}
\hline Regulation of Coherence-Incoherence & \multirow{2}{*}{ CORE-OM } & 35.020 & 3 & 260 & .000 & .288 \\
& & BSI & 16.593 & 3 & 260 & .000 & .161 \\
\cline { 2 - 7 } & 2 & CORE-OM & 19.719 & 3 & 161 & .000 & .269 \\
& & BSI & 10.047 & 3 & 161 & .000 & .158 \\
\hline Regulation of Self-esteem-Self-criticism & \multirow{2}{*}{1} & CORE-OM & 49.767 & 3 & 260 & .000 & .365 \\
& & BSI & 20.264 & 3 & 260 & .000 & .190 \\
\cline { 2 - 8 } & 2 & CORE-OM & 27.973 & 3 & 161 & .000 & .343 \\
& & BSI & 10.568 & 3 & 161 & .000 & .165 \\
\hline
\end{tabular}

Note. Group 1 = Non-disordered individuals; Group 2 = Disordered individuals.

In all polarities, there was a significant effect of the degree of regulation on both BSI and CORE-OM, separately considered, using a Bonferroni adjusted $\alpha$ of .025 (in all polarities and groups, $p<.001$, with the exception of the polarity pleasure-pain, in the group of disordered individuals, with $p=.002$ ).

To find out in which groups those differences occurred, we performed multiple comparisons of means with Scheffe post hoc test. Table 11 presents the mean scores on symptomatology of the four groups based on the degree of regulation of all dialectical polarities, both within non-disordered (group 1) and disordered (group 2) individuals, also indicating the number of participants per group.

Table 11. Number of participants and mean scores on symptomatology (CORE-OM and BSI) of the 4 groups of dialectical polarities, within non-disordered and disordered individuals

\begin{tabular}{|c|c|c|c|c|c|c|c|c|c|c|c|c|c|c|}
\hline \multirow{2}{*}{$\begin{array}{l}\text { Polarities } \\
\text { Groups }\end{array}$} & \multicolumn{2}{|c|}{ PP } & \multicolumn{2}{|c|}{ PD } & \multicolumn{2}{|c|}{ PL } & \multicolumn{2}{|c|}{ CC } & \multicolumn{2}{|c|}{ AET } & \multicolumn{2}{|c|}{ CI } & \multicolumn{2}{|c|}{ SS } \\
\hline & $N$ & $M$ & $N$ & M & $N$ & $M$ & $N$ & $M$ & $N$ & $M$ & $N$ & M & $N$ & M \\
\hline \multicolumn{15}{|l|}{ Group 1- CORE } \\
\hline $1(--)$ & 56 & .94 & 65 & .97 & 65 & 1.05 & 58 & .92 & 65 & 1.00 & 56 & 1.05 & 69 & 1.03 \\
\hline $2(-+)$ & 46 & .91 & 37 & .71 & 36 & .74 & 38 & .89 & 51 & .67 & 34 & .72 & 33 & .82 \\
\hline $3(+-)$ & 60 & .50 & 49 & .70 & 38 & .66 & 37 & .67 & 28 & .86 & 31 & .68 & 53 & .56 \\
\hline $4(++)$ & 102 & .51 & 113 & .47 & 125 & .45 & 131 & .49 & 120 & .44 & 143 & .50 & 109 & .44 \\
\hline Total & 264 & & 264 & & 264 & & 264 & & 264 & & 264 & & 264 & \\
\hline \multicolumn{15}{|l|}{ Group 1 - BSI } \\
\hline $1(--)$ & 56 & .74 & 65 & .83 & 65 & .81 & 58 & .76 & 65 & .78 & 56 & .81 & 69 & .79 \\
\hline $2(-+)$ & 46 & .75 & 37 & .63 & 36 & .63 & 38 & .62 & 51 & .57 & 34 & .66 & 33 & .67 \\
\hline $3(+-)$ & 60 & .51 & 49 & .58 & 38 & .60 & 37 & .69 & 28 & .78 & 31 & .60 & 53 & .55 \\
\hline $4(++)$ & 102 & .45 & 113 & .41 & 125 & .44 & 131 & .45 & 120 & .43 & 143 & .46 & 109 & .43 \\
\hline Total & 264 & & 264 & & 264 & & 264 & & 264 & & 264 & & 264 & \\
\hline \multicolumn{15}{|l|}{ Group 2- CORE } \\
\hline $1(--)$ & 79 & 1.75 & 93 & 1.87 & 102 & 1.79 & 88 & 1.79 & 102 & 1.78 & 103 & 1.81 & 86 & 1.83 \\
\hline $2(-+)$ & 50 & 1.72 & 28 & 1.52 & 20 & 1.55 & 22 & 1.42 & 16 & .84 & 20 & 1.56 & 41 & 1.69 \\
\hline $3(+-)$ & 15 & 1.09 & 17 & 1.17 & 18 & 1.26 & 24 & 1.49 & 25 & 1.78 & 18 & 1.19 & 15 & .85 \\
\hline $4(++)$ & 21 & .93 & 27 & .87 & 25 & .94 & 31 & 1.16 & 22 & .93 & 24 & .89 & 23 & .89 \\
\hline Total & 165 & & 165 & & 165 & & 165 & & 165 & & 165 & & 165 & \\
\hline \multicolumn{15}{|l|}{ Group 2 - BSI } \\
\hline $1(--)$ & 79 & 1.57 & 93 & 1.69 & 102 & 1.63 & 88 & 1.69 & 102 & 1.62 & 103 & 1.81 & 86 & 1.66 \\
\hline $2(-+)$ & 50 & 1.54 & 28 & 1.46 & 20 & 1.40 & 22 & 1.26 & 16 & .91 & 20 & 1.31 & 41 & 1.48 \\
\hline $3(+-)$ & 15 & 1.10 & 17 & 1.14 & 18 & 1.17 & 24 & 1.45 & 25 & 1.51 & 18 & 1.23 & 15 & 1.06 \\
\hline $4(++)$ & 21 & 1.13 & 27 & .90 & 25 & 1.05 & 31 & .98 & 22 & 1.08 & 24 & .99 & 23 & 1.00 \\
\hline Total & 165 & & 165 & & 165 & & 165 & & 165 & & 165 & & 165 & \\
\hline
\end{tabular}

Note. PP = Pleasure-Pain; PD = Proximity-Differentiation; PL = Productivity-Leisure; CC = Control-Cede/Cooperation; AET = Actualization/Exploration-Tranquility; CI = Coherence-Incoherence; SS = Self-esteem-Self-criticism; Group 1 = Non-disordered individuals; Group 2 = Disordered individuals.

Overall, the group with the least symptomatology (CORE-OM/BSI) was group $4(++)$, followed by groups $3(+-), 2(-+)$, and $1(--)$, displaying this last group the highest mean on symptomatology, both within non-disordered and disordered individuals. However, there were a few and non-significant exceptions in some groups of pleasure-pain, actualization/exploration-tranquility and self-esteem-selfcriticism (for further details, see Sol, 2012).

\section{DISCUSSION AND CONCLUSIONS}

The present study addressed the relationships between regulation and discrepancy in psychological needs satisfaction and symptomatology.

Regarding the correlations between those variables, as expected, the degree of regulation seems to 
be negatively related to symptomatology, whereas discrepancy seems to be positively related to it. As aforesaid, the degree of regulation of all dialectical polarities and psychological needs suggested by the PCM correlated negatively with symptomatology. The strength of those correlations was large in all dialectical polarities and in almost all psychological needs. Considering the discrepancies, only in two polarities, proximity-differentiation and coherence-incoherence, there was no association with symptomatology. In all the others, there was a positive association, corresponding higher levels of discrepancy to higher levels of symptomatology and lower levels of discrepancy to lower levels of symptomatology. Therefore, our hypothesis 1 was almost fully confirmed. Although the discrepancies' results were neither so consistent nor so robust as the regulation's ones, they were nevertheless relevant, suggesting the importance of discrepancy in psychological needs satisfaction as related to symptomatology.

Nevertheless, we were surprised by the absence of a correlation between discrepancy in proximitydifferentiation and coherence-incoherence, and symptomatology, since their degree of regulation was the best predictor of both BSI and CORE-OM. Therefore, it seems that the relationships of symptomatology with the degree of regulation, on one hand, and with balance versus discrepancy, on the other, are different, suggesting the importance of further researching these questions to better understand how and to what extent the degree of regulation and the balance versus discrepancy contribute to symptomatology.

Regarding the predictive power of the degree of regulation of psychological needs satisfaction in relation to symptomatology, we saw that both needs individually considered and dialectical polarities predicted part of the global variance in symptomatology, both in BSI and CORE-OM, hence supporting our hypothesis 2 .

Regarding the needs individually considered, special attention should be paid to tranquility, proximity, and self-esteem, since these three were part of the best model both for BSI and CORE-OM. The fact that proximity and self-esteem were some of the most predictive needs is in tandem with several theories and studies on psychological needs (e.g., Blatt, 2006, 2008; Deci \& Ryan, 2000; Epstein, 1993; Grawe, 2004; Sheldon et al., 2001 É a 1av vez que é citado. Deve estar completa; Vasco, 2012).

We should reflect a little bit more on the importance of tranquility, as this need is not included in the aforesaid main theories of psychological needs, with the exception of the PCM that suggests it in the polarity actualization/exploration-tranquility (e.g., Vasco, 2012). The relevance of tranquility empirically supported by the results of the present study can contribute to explain the effectiveness of some techniques of therapeutic intervention, such as mindfulness. The effectiveness of this technique in therapy has already obtained evidence in several studies (McKay, Wood, \& Brantley, 2007). One of the possible explanations for this fact can be that mindfulness enhances the ability to regulate the need for tranquility, which, in turn, contributes to the reduction of symptoms. Therefore, it is important to investigate it further.

Regarding the predictive value of dialectical polarities put forward by the PCM, as we saw previously, proximity-differentiation and coherence-incoherence were part of the best models both for BSI and CORE-OM. These results are consistent with the literature on psychological needs. In fact, the main theories refer both needs of the polarity proximity-differentiation (e.g., Blatt, 2006, 2008; Deci \& Ryan, 2000; Sheldon et al., 2001). Apart from this, Faria and Vasco (2011) found out that one of the best predictors of the global variance in BSI was coherence-incoherence.

Overall supporting our hypothesis 3, the group with a high degree of regulation of both needs of each dialectical polarity displayed the lowest symptomatology (BSI/CORE-OM), both within nondisordered and disordered individuals. These results are consistent with those found with a convenience non-clinical sample and referring to the levels of psychological well-being and distress, by Bernardo (2011), for proximity/differentiation, Rucha (2011), for productivity/leisure, Fonseca (2011), for control/cede-cooperation, and Rodrigues (2010), for coherence/incoherence. In all these studies, as aforesaid, the group with a high degree of regulation of both poles displayed the highest level of wellbeing and the lowest level of distress. Faria and Vasco (2011) also found out, in a clinical sample, that the group with the lowest symptoms, measured with BSI, was the one with a high degree of regulation of both poles of proximity/differentiation and control/cede-cooperation.

In our study, there were, however, some exceptions regarding pleasure/pain, actualizationexploration/tranquility and self-esteem/self-criticism. Nevertheless, those exceptions lose importance as they did not occur in all groups/subgroups and measures, and, in all of them, group $4(++)$ immediately followed the group with the lowest symptomatology, without significant differences between them in any case.

Therefore, although these results should be interpreted with caution, due to the different size of the groups, they once more empirically support the PCM both in its theory of disorder and in its concept of psychological needs as dialectical polarities. The ability to regulate both poles of each polarity, in a never 
ending ongoing process of negotiating and balancing, seems to be crucial for mental health. It was precisely the group with a high degree of regulation of both needs of each dialectical polarity that had the lowest symptoms, with a few and non-significant exceptions.

Moreover, this has also been the case of the polarities that imply needs commonly seen as dystonic (incoherence, pain and self-criticism). In fact, incoherence was one of the most predictive needs of the global variance in symptomatology measured with the BSI. These results seem to support the PCM's idea that there are no a priori good (syntonic) or bad (dystonic) needs, suggesting the construct of "needs without valence", meaning that needs are adaptive or non-adaptive depending on context (Conceição \& Vasco, 2005).

Although the discrepancies' results were not so consistent nor so robust as the regulation's ones, they were still relevant, suggesting the importance of balance in psychological needs satisfaction for mental health, which is consistent with the results found out by Sheldon and Niemiec (2006) for wellbeing. From another point of view, it is possible to consider balance as a form of consistency and discrepancy as a form of inconsistency, like in Grawe's theory (2004). The results of the present study suggest that discrepancy seems to contribute to symptomatology, with detrimental consequences to mental health.

However, this study has some limitations. It was the first time that the ERSN was used as a global measure. Apart from this, we used only self-reports to measure the variables in study and had a convenience sample with a disproportion on gender with significant more females than males and a great range of age (18-77 years).

The empirical support stemming from this study regarding the importance of the regulation of psychological needs satisfaction as related to symptomatology, suggests the relevance of further research. Many other questions await for an answer. For instance, from a clinical point of view, it may be interesting to study which dialectical polarities contribute the most for certain kinds of disorders, calling the practitioner's attention to the needs that should be addressed in a given clinical case. Another relevant question refers to the own structure of dialectical polarities, how they are organized and how they relate to one another, allowing horizontal (between both poles of each polarity) and vertical (among the several polarities) conflicts. To this extent, it would be interesting to compare groups based on combinations of the degrees of regulation of needs from different polarities, on the level of symptomatology, well-being, and distress, especially combining needs commonly seen as dystonic (pain, incoherence and selfcriticism). In other words, this would be to test the PCM's theory of needs vertically. This could also be done for the balance in psychological needs satisfaction, by analyzing vertical discrepancies (between needs from different polarities).

Apart from this, it would also be interesting to study the differences on the regulation of psychological needs satisfaction and symptomatology by gender, and to investigate to what extent the developmental phase may influence the relationships between those variables. This study tested the PCM's psychological needs theory in the perspective of overall symptomatology, without looking at any disorder in particular. It would be interesting to look at specific disorders and try to understand their etiology in terms of dysregulation of certain psychological needs, or how they affect their regulation.

Regarding implications for clinical practice, the results of the present study suggest the importance of taking into account regulation and discrepancy in psychological needs satisfaction for case conceptualization, as these variables can be considered relevant criteria for clinical decision-making (Faria \& Vasco, 2011). Apart from this, one of the therapeutic goals that may make sense for a significant number of patients is to help them to acknowledge, accept, experience, and act upon regulation and balance in psychological needs satisfaction (Faria \& Vasco, 2011; Vasco, 2009; Vasco, Faria, Vaz, \& Conceição, 2010). So, it seems to be important for therapists to pay attention to intervention techniques especially suited to improve patients' ability to regulate and balance their needs satisfaction. For instance, for proximity, it may be useful to identify and work on markers of the therapeutic alliance's ruptures through metacommunication, in order to provide patients with "corrective emotional experiences" (Safran \& Muran, 2000; Vasco, 2005, 2009). Further, still regarding proximity and particularly self-esteem, validation and empathy may be adequate (Greenberg \& Elliott, 1997; Rogers, 1957; Vasco, 2009). As previously mentioned, mindfulness can be particularly effective to enhance the regulation of tranquility (McKay et al., 2007). Concerning pain and control/cede, it may be useful to work out with patients distress tolerance skills, namely the ones suggested by the Dialectical Behavior Therapy developed by Marsha Linehan (1993a, 1993b). Finally, for the enhancement of coherence-incoherence of the Self, Vasco (2009) suggests the emotional validation of patients' conflicts and inconsistencies, helping them to build more coherent narratives (Vasco, 2007), two-chair work to deal with self-splits, and empty-chair work to deal with unfinished business should be considered (e.g., Greenberg, 2002). 
Putting it all together, we would suggest that addressing psychological needs in psychotherapy is necessarily needed!

\section{References}

Bernardo, F. (2011). Necessidades psicológicas de proximidade e autonomia: Relação com bem-estar e malestar psicológicos [Psychological needs of proximity and autonomy: Relationship with psychological well-being and distress] (Master's thesis, Faculty of Psychology of University of Lisbon, Lisbon, Portugal). Retrieved from http://hdl.handle.net/10451/4998

Blatt, S. J. (2006). A fundamental polarity in psychoanalysis: Implications for personality development, psychopathology and the therapeutic process. Psychoanalytic Inquiry, 26(4), 494-520. https://doi.org/10.1080/07351690701310581

Blatt, S. J. (2008). Polarities of experience: Relatedness and self-definition in personality development, psychopathology, and the therapeutic process. Washington, DC, USA: American Psychological Association.

Cadilha, N. (2010). Regulação da satisfação das necessidades de prazer e dor: Relações com o bem-estar e distress psicológico [Regulation of needs of pleasure and pain satisfaction: Relationships with psychological well-being and distress] (Master's thesis, Faculty of Psychology of University of Lisbon, Lisbon, Portugal). Retrieved from http://hdl.handle.net/10451/2690

Calinas, L. (2011). Necessidade psicológica de exploração/tranquilidade: Relação com bem-estar e distress psicológico [Psychological need of exploration/tranquility: Relationship with psychological well-being and distress] (Master thesis). Lisbon: Faculty of Psychology of University of Lisbon.

Canavarro, M. C. (2007). Inventário de Sintomas Psicopatológicos (BSI): Uma revisão crítica dos estudos realizados em Portugal [The Brief Symptom Inventory (BSI): A critical revision of the studies carried out in Portugal]. In M. R. Simões, C. Machado, M. M. Gonçalves, \& L. S. Almeida (Eds.), Avaliação psicológica: Instrumentos validados para a população portuguesa (vol. III, pp. 305-330). Coimbra: Quarteto.

Conceição, N., \& Vasco, A. B. (2005). Olhar para as necessidades do self como um boi para um palácio: Perplexidades e fascínio [To stare at the self's needs like a stuck pig: Perplexities and fascination]. Psychologica, 40, 55-73.

Conde, E. (2012). Dialéctica de polaridades de regulação da satisfação de necessidades psicológicas: Relações com o bem-estar e distress psicológicos [Dialectic of polarities of regulation of psychological needs satisfaction: Relationships with psychological well-being and distress] (Master's thesis, Faculty of Psychology of University of Lisbon, Lisbon, Portugal). Retrieved from http://hdl.handle.net/10451/8177

Deci, E. L., \& Ryan, R. M. (2000). The "what" and "why" of goal pursuits: Human needs and the selfdetermination of behavior. Psychological Inquiry, 11, 227-268. http://dx.doi.org/10.1207/S15327965PLI1104_01

Derogatis, L. R. (1993). BSI: Brief Symptom Inventory (3 $3^{\text {rd }}$ ed.). Minneapolis: National Computers Systems.

Epstein, S. (1990). Cognitive-experiential self-theory. In L. A. Pervin (Ed.), Handbook of personality: Theory and research (pp. 165-192). New York: Guilford Press.

Epstein, S. (1991). Cognitive-experiential self-theory: An integrative theory of personality. In R. C. Curtis (Ed.), The relational self: Theoretical convergences in Psychoanalysis and Social Psychology (pp. 111137). New York: Guilford Press.

Epstein, S. (1993). Implications of cognitive-experiential self-theory for personality and developmental psychology. In D. Funder, R. Parke, C. Tomlinson-Keasey, \& K. Widamen (Eds.), Studying lives through time: Personality and development (pp. 399-438). Washington, DC: American Psychological Association.

Epstein, S. (2003). Cognitive-experiential self-theory of personality. In T. Millon, M. J. Lerner, \& I. B. Weiner (Eds.), Handbook of Psychology, Vol. 5: Personality and Social Psychology (pp. 159-184). Hoboken, NJ: John Wiley \& Sons.

Evans, C., Mellor-Clark, J., Margison, F., Barkham, M., Audin, K., Connell, J., \& McGrath, G. (2000). CORE: Clinical Outcomes in Routine Evaluation. Journal of Mental Health, 9, 247-255. http://dx.doi.org/10.1080/jmh.9.3.247.255

Faria, J., \& Vasco, A. B. (2011). Needs necessarily needed: A guide for clinical decision-making. Paper presented at the $27^{\text {th }}$ Conference of the Society for the Exploration of Psychotherapy Integration: Crossing the divide: SEPI's unique place in bridging the science-practice gap. Washington, DC, USA.

Fonseca, T. (2011). Necessidade psicológica de controlo/cedência: Relação com bem-estar e distress psicológicos [Psychological need of control/cede: Relationship with psychological well-being and distress] (Master's thesis, Faculty of Psychology of University of Lisbon, Lisbon, Portugal). Retrieved 
from http://hdl.handle.net/10451/4868

Grawe, K. (2004). Psychological therapy. Bern: Hogrefe \& Huber Publishers.

Greenberg, L. S. (2002). Emotion-focused therapy: Coaching clients to work through their feelings. Washington, DC: American Psychological Association.

Greenberg, L. S., \& Elliott, R. (1997). Varieties of empathic responding. In A. Bohart \& L. Greenberg (Eds.), Empathy reconsidered: New directions in psychotherapy (pp. 167-186). Washington, DC: American Psychological Association.

Guerreiro, D. (2011). Necessidade psicológica de auto-estima/auto-crítica: Relação com bem-estar e distress psicológico [Psychological need of self-esteem/self-criticism: Relationship with psychological well-being and distress] (Master's thesis, Faculty of Psychology of University of Lisbon, Lisbon, Portugal). Retrieved from http://hdl.handle.net/10451/4960

Linehan, M. M. (1993a). Cognitive-behavioral treatment of borderline personality disorder. New York: Guilford Press.

Linehan, M. M. (1993b). Skills training manual for treating borderline personality disorder. New York: Guilford Press.

Maroco, J. (2007). Análise estatística com utilização do SPSS [Statistical analysis with the use of SPSS] (3 ${ }^{\text {rd }}$ ed.). Lisbon: Edições Sílabo.

Maslow, A. (1954). Motivation and personality. New York: Harper \& Row.

McKay, M., Wood, J. C., \& Brantley, J. (2007). The Dialectical Behavior Therapy skills workbook: Practical DBT exercises for learning mindfulness, interpersonal effectiveness, emotion regulation and distress tolerance. Oakland: New Harbinger Publications.

Rodrigues, C. (2010). Necessidade psicológica de coerência/incoerência: Relação com bem-estar e distress psicológico [Psychological need of coherence/incoherence: Relationship with psychological well-being and distress] (Master's thesis, Faculty of Psychology of University of Lisbon, Lisbon, Portugal). Retrieved from http://hdl.handle.net/10451/6061

Rogers, C. R. (1957). The necessary and sufficient conditions of therapeutic personality change. Journal of Consulting Psychology, 21(2), 95-103. https://doi.org/10.1037/h0045357

Rucha, S. (2011). Necessidade psicológica de produtividade/lazer: Relação com bem-estar e distress psicológico [Psychological need of productivity/leisure: Relationship with psychological well-being and distress] (Master's thesis, Faculty of Psychology of University of Lisbon, Lisbon, Portugal). Retrieved from http://hdl.handle.net/10451/4991

Safran, J. D., \& Muran, J. C. (2000). Negotiating the therapeutic alliance: A relational treatment guide. New York: The Guilford Press.

Sales, C. M. D., Moleiro, C., Evans, C., \& Alves, P. C. G. (2012). Versão portuguesa do CORE-OM: Tradução, adaptação e estudo preliminar das suas propriedades psicométricas [Portuguese version of COREOM: Translation, adaptation and preliminary study on its psychometric properties]. Revista de Psiquiatria Clínica, 39(2), 54-59.

Sheldon, K. M., \& Niemiec, C. P. (2006). It's not just the amount that counts: Balanced need satisfaction also affects well-being. Journal of Personality and Social Psychology, 91(2), 331-341. https://doi.org/10.1037/0022-3514.91.2.331

Sheldon, K. M., Elliot, A. J., Kim, Y., \& Kasser, T. (2001). What is satisfying about satisfying events? Testing 10 candidate psychological needs. Journal of Personality and Social Psychology, 80(2), 325-339. https://doi.org/10.1037//0022-3514.80.2.325

Sirgy, M. J., \& Wu, J. (2009). The pleasant life, the engaged life, and the meaningful life: What about the balanced life? Journal of Happiness Studies, 10, 183-196. https://doi.org/10.1007/s10902-0079074-1

Sol, A. (2012). Relações entre sintomatologia e necessidades e bem-estar e distress psicológicos [Relationships between symptomatology and psychological needs, well-being and distress] (Master's thesis, Faculty of Psychology of University of Lisbon, Lisbon, Portugal). Retrieved from http://hdl.handle.net/10451/7648

Vasco, A. B. (2005). A conceptualização de caso no modelo de complementaridade paradigmática: Variedade e integração [The case conceptualization in the Paradigmatic Complementarity Model: Variety and integration]. Psychologica, 40, 11-36.

Vasco, A. B. (2007). Quando Menos é Melhor: A Arte de Comunicar em Psicoterapia [When less is better: The art of communicating in psychotherapy]. Paper presented at the International Meeting "Communication and Health", Azores University, Ponta Delgada, Portugal.

Vasco, A. B. (2009). Regulation of needs satisfaction as the touchstone of happiness. Paper presented at the $16^{\text {th }}$ Conference of the European Association for Psychotherapy: Meanings of Happiness and Psychotherapy, Lisbon, Portugal. 
Vasco, A. B. (2012). Quando um peixe encarnado nos começa, de súbito, a revelar a sua também cor negra, pintemo-lo, então, digamos, de amarelo: Em volta da integração em Psicoterapia [When a red fish suddenly begins to show us its black color as well, let's paint it then, let's say, of yellow: Around the integration in psychotherapy]. Paper presented at the $1^{\text {st }}$ National Meeting of the Portuguese Psychologists Bar, Lisbon, Portugal.

Vasco, A. B., \& Velho, C. (2010). The integrative essence of seven dialectical needs polarities. Paper presented at the $26^{\text {th }}$ Conference of the Society for the Exploration of Psychotherapy Integration: One or many sciences for Psychotherapy Integration: What constitutes evidence?, Florence, Italy.

Vasco, A. B., Bernardo, F., Cadilha, N., Calinas, L., Conde, E., Fonseca, T., Guerreiro, D., Rodrigues, C., \& Rucha, S. (2012). Escala de Regulação da Satisfação de Necessidades Psicológicas (ERSN) [Psychological Needs Satisfaction Regulation Scale (ERNS)] (Unpublished document). Lisbon: Faculty of Psychology of University of Lisbon.

Vasco, A. B., Faria, J., Vaz, F. M., \& Conceição, N. (2010). Adaptation, disorder and the therapeutic process: Needs or emotional dysregulation? Paper presented at the $26^{\text {th }}$ Conference of the Society for the Exploration of Psychotherapy Integration: One or many sciences for Psychotherapy Integration: What constitutes evidence?, Florence, Italy.

Historial do artigo

Recebido 22/04/2016

Aceite $\quad 27 / 01 / 2017$

Publicado $\quad 07 / 2017$ 
Psychological needs satisfaction and symptomatology 